\title{
A importância do ensino da relação médico-paciente $e$ das habilidades de comunicação na formação do profissional de saúde
}

\author{
The importance of teaching doctor-patient relationships and \\ communication abilities in health professional education
}

\author{
La importancia del enser̃o de la relation medico-paciente y de \\ las habilidades de la comunication en la formación de los \\ profesionais de salud
}

Ana Cecília Sucupira ${ }^{1}$

A relação médico-paciente, nas últimas décadas, vem ganhando cada vez mais espaço na literatura internacional. Entretanto, pouco se tem avançado no que se refere à inserção desse tema na formação do médico. Isso é especialmente verdadeiro no nosso país (Grosseman \& Patrício, 2004). O artigo de Roger Ruiz-Moral sobre Relação médico-paciente: desafios para a formação de profissionais de saúde coloca em pauta esse tema fundamental para a prática clínica, e chama atenção sobre os aspectos referentes à inserção dessa temática na educação médica.

É possível afirmar que há uma defasagem entre o modo como a literatura internacional discute a relação médico-paciente e os temas de humanização e o espaço que é dado à discussão dos aspectos referentes às diversas formas como se dá a relação entre o médico e o paciente no contexto da atenção médica no Brasil (Leite et al., 2007). Predomina, ainda, o interesse na incorporação de procedimentos sofisticados e nos equipamentos de ponta. Mais recentemente, no âmbito do SUS, a Política Nacional de Humanização - o Humaniza-SUS, tem contribuído para inserir essa discussão nos serviços de saúde, ampliando o tema para a relação entre as diversas categorias dos profissionais de saúde e o usuário (Brasil, 2006a). A discussão sobre o Acolhimento, que vem sendo feita nas diversas instâncias do SUS, também tem como foco principal a relação entre os profissionais de saúde e os usuários. ${ }^{1}$ Médica; doutora em Pediatria; professora, departamento de Pediatria, Faculdade de Medicina, Universidade de São Paulo. São
Paulo, SP. <asucupira@yahoo.com>

Rua Senador César Lacerda Vergueiro, 488

Vila Madalena - São Paulo, SP

05.435-010 
No campo acadêmico, várias teses abordam a relação médico-paciente, sob diferentes perspectivas (Guimarães, 2005; Sucupira, 1982). Contudo, chama atenção a inexistência de livros didáticos sobre o assunto dirigidos aos alunos. A relação médico-paciente ainda se constitui um tema marginal, frente à hegemonia do modelo biológico organicista que domina a formação médica no nosso meio. As tentativas anteriores de inserir esse tema no currículo médico, que aconteceram em algumas faculdades de medicina, ocorreram no interior de disciplinas optativas ou consideradas de menor importância, como na psicologia, sociologia médica ou antropologia médica. Tentativas essas que não tiveram muito êxito. Atualmente, pode-se observar que o movimento ético e humanitário no interior da profissão médica, citado pelo autor, começa a ter repercussões no meio acadêmico, e em algumas universidades a abordagem de temas referentes à bioética no currículo médico começa a introduzir, para os alunos, a discussão da relação médico-paciente.

O autor aponta ainda - entre os motivos que vêm contribuindo para evidenciar a necessidade de se buscar uma relação mais personalizada e humanizada entre o médico e o paciente -, o reconhecimento, por parte da clientela, dos seus direitos e responsabilidades. Este é ainda um caminho longo a ser percorrido pela grande maioria dos usuários dos serviços de saúde no Brasil e é um dos pontos de destaque abordados pelo Humaniza-SUS (Brasil, 2006b).

Por fim, o autor ressalta os efeitos da relação médico-paciente no resultado das intervenções sanitárias. O efeito terapêutico da relação médico-paciente é reconhecido há bastante tempo, entretanto, as mudanças ocorridas na prática médica, nas últimas décadas, colocam uma importância bem mais evidente para os aspectos relacionais do atendimento (Ballint, 1988). As doenças infecciosas, nas quais a intervenção médica tinha um efeito curativo imediato, dão lugar às doenças crônico-degenerativas, em que esse aspecto é substituído pela necessidade de se encontrarem estratégias de tratamento que possam proporcionar melhor qualidade de vida. Tratamentos que se caracterizam pela longa duração e pela absoluta necessidade de participação intensa do paciente. Nessas circunstâncias, o relacionamento que se estabelece entre o profissional e o médico passa a ter uma importância fundamental para a adesão às propostas terapêuticas e para o sucesso das intervenções.

No entanto, vale ainda comentar a importância da relação médico-paciente nos atendimentos de urgência ou na modalidade pronto atendimento. Nesta última situação, a angústia do paciente e dos familiares não pode ser vista como um fator que transtorna o ambiente de trabalho do profissional, mas deve ser pensada como um aspecto do atendimento a ser abordado. Nos serviços de pronto-atendimento, no modelo centrado na doença, calcado na díade queixa-conduta, o atendimento prestado resume-se a dar uma resposta imediata, visando despachar o mais depressa possível a clientela em função do acúmulo de demanda. $\mathrm{O}$ foco é a doença, e não o indivíduo. A baixa resolutividade desse modelo faz com que o paciente retorne várias vezes ao serviço, aumentando cada vez mais a demanda. Esse é um círculo vicioso que leva à insatisfação tanto dos profissionais quanto dos usuários.

As novas demandas trazidas para o consultório médico, com questões mais sociais, como a violência, o alcoolismo, problemas relacionados ao casamento, ao emprego, às dificuldades na vida escolar, entre outros, exigem do profissional outras habilidades (de escuta, de comunicação), que vão além dos conhecimentos estritamente biomédicos. Nessa perspectiva, a formação do médico requer outros atributos que ampliem a sua atuação.

Nesse ponto, é preciso ressaltar a posição do autor ao destacar "a própria natureza e características da Relação Clínica, que a convertem em um exemplo paradigmático do que representa a essência da educação médica, já que por meio do ensino da Relação Clínica chegamos ao autêntico núcleo curricular ("core currículo") do ensino da medicina".

Ao se propor a desvelar a natureza da relação clínica, o autor afirma, em primeiro lugar, que essa relação, enquanto um procedimento, necessita de teorias que lhe dêem suporte. Cita, então, a necessidade de se ampliar o ensino, incorporando conhecimentos das áreas humanas, além da teoria biomédica. Nesse sentido, falta, por parte do autor, uma referência à 
antropologia e à sociologia. É fundamental contextualizar essa relação e entender as representações que os atores têm um do outro e da instituição onde ocorre essa relação.

Um aspecto importante abordado em todo o texto é a valorização do paciente como o centro e o objeto da atenção. Assim, é importante que os resultados do atendimento sejam considerados também sob o ponto de vista dos objetivos trazidos pelo paciente e não somente aqueles colocados pela queixa, inserida no modelo biomédico. Isto implica considerar as necessidades do paciente para além da queixa orgânica que ele explicita. Em seguida, o autor aponta a importância da formação pessoal e ética do médico, enquanto parte dessa relação, considerando que, na intervenção, o médico é, em si. uma ferramenta (Van der Molen \& Lang, 2007).

Finalmente, como quarta característica da relação clínica ou relação médico-paciente, o autor destaca a importância de serem incorporadas as habilidades técnicas e a necessidade de se particularizar a aplicação dessa técnica por meio da atitude reflexiva que considera cada encontro como único e singular. Complementa ainda, ressaltando a importância da prática reflexiva em oposição à prática automatizada, com base na incorporação da técnica e de sua aplicação particularizada. Um aspecto que chama atenção, em vários textos que falam sobre as habilidades da consulta, é a não referência ao contexto mais amplo em que ela ocorre (Van der Molen \& Lang, 2007).

Dessa forma, na possibilidade de particularização da técnica, não são considerados os limites dados pelos outros determinantes da consulta, tais como a instituição onde ela acontece, e as inserções sociais dos atores envolvidos.

Todo o texto caracteriza-se por priorizar a visão do paciente e do médico enquanto pessoas, sujeitos ativos, na realização do ato clínico e, portanto, a necessidade de novos referenciais teóricos para dar suporte à introdução de novas técnicas de ensino para se alcançar uma prática mais reflexiva e fenomenológica.

Entretanto, ao considerar a relação médico-paciente como uma técnica ou um procedimento, que pode e deve ser apreendido por meio de protocolos, guias e regras, para depois ser, devidamente, adequado à subjetividade dos participantes, o autor reduz o caráter dessa relação. Pode surgir, então, uma confusão entre habilidades de comunicação e relação médico-paciente. Uma relação que se dá entre dois sujeitos sociais e que se caracteriza por ser uma relação assimétrica, tanto em função do saber envolvido, quanto, muitas vezes, das inserções sociais desses atores. A relação médico-paciente pode expressar-se enquanto uma tecnologia de processo, que vai além de uma técnica ou um procedimento. A questão estritamente técnica que essa relação envolve está apoiada nas técnicas de comunicação, imprescindíveis para que se possa ter a compreensão necessária entre os atores para o esclarecimento dos objetivos desse ato clínico, e para adequar a natureza da relação às diferenças culturais e sociais dos sujeitos em relação. Muitas das publicações sobre as habilidades de consulta restringem-se aos aspectos da comunicação e expressam tipos e modelos de relação, sem que se considere o contexto onde elas ocorrem. É fundamental que se considerem todos os determinantes envolvidos nessa relação, sobretudo, o tipo de instituição em que ela ocorre, entendendo suas finalidades e seu funcionamento.

A compreensão mais ampla do paciente e de suas demandas não se esgota no domínio de uma técnica, mas implica a necessidade de uma formação mais ampla nas ciências humanas, o que vai se expressar nas atitudes, posturas e condutas adotadas nessa relação. Uma formação que, ao longo do curso, dê condições ao aluno de entender a própria natureza da profissão médica. Desse modo, que permita ao futuro profissional ter uma postura não somente ética, mas com uma profunda dimensão de solidariedade, necessária para lidar com o sofrimento humano. E possibilite, assim, entender o paciente enquanto um sujeito portador de um sofrimento que precisa ser acolhido.

A inserção do ensino da relação médico-paciente deve ocorrer em duas instâncias. Do ponto de vista teórico, é fundamental a introdução, no currículo, de saberes próprios às 
áreas de humanidades, com conteúdos voltados para a relação entre esses atores, tais como: psicologia, sociologia, antropologia e comunicação. Em relação à prática, é importante a observação de consultas realizadas pelos alunos, tanto diretamente, como por meio de videofilmagens. Essas últimas permitem aos alunos reverem seus comportamentos e atitudes, possibilitando a discussão do significado de cada postura assumida. Como assinala o autor, é fundamental que a discussão e o ensino da relação médico-paciente tenham início o mais precocemente possível no currículo médico. Vale ressaltar que, na prática, embora não exista, formalmente, uma disciplina, os diferentes modelos de relação médico-paciente são passados, para os alunos, por meio dos professores, sem que haja uma discussão desses modelos, que vão se cristalizando no aluno ao longo dos anos. A análise das diversas posturas e atitudes possibilitaria ao aluno construir uma visão crítica e permitiria entender as potencialidades e prejuízos decorrentes do tipo de relação que se estabelece entre o médico e o paciente.

Entretanto, não se pode pensar, de forma isolada, o desafio de inserir a relação médicopaciente na formação dos profissionais de saúde, sem que se redirecione todo o processo da educação médica, de tal forma a construir uma proposta de ensino que, junto com a aquisição das habilidades biomédicas, priorize a formação humanitária e ética do profissional que terá, como missão, cuidar do sofrimento humano.

\section{Referências}

BALLINT, M. O médico, seu paciente e a doença. São Paulo: Livraria Atheneu, 1988.

BRASIL. Ministério da Saúde. Secretaria de Atenção à Saúde. Núcleo técnico da Política Nacional de Humanização. Acolhimento nas práticas de produção de saúde. 2.ed. Brasília: Ministério da Saúde, $2006 a$. (Série B. Textos Básicos de Saúde).

. Ministério da Saúde. Humaniza-SUS: documento base para gestores e trabalhadores do SUS. 3.ed. Brasília: Ministério da Saúde, 2006b.

GROSSEMAN, S.; PATRÍCIO, Z.M. A relação médico-paciente e o cuidado humano: subsídios para a formação da educação médica. Rev. Bras. Educ. Méd., v.28, n.2, p.99-105, 2004.

GUIMARÃES, M.B.L. Intuição, pensamento e ação na clínica. Interface - Comunic., Saúde, Educ., v.9, n.17, p.317-32, 2005.

LEITE, A.J.M.; CAPRARA, A.; COELHO FILHO, J.M. (Orgs.). Habilidades de comunicação com pacientes e famílias. São Paulo: Sarvier, 2007.

SUCUPIRA, A.C.S.L. Relações médico-paciente nas instituições de saúde brasileiras. 1982. Dissertação (Mestrado) - Departamento de Medicina Preventiva, Universidade de São Paulo, São Paulo.

VAN DER MOLEN, H.T.; LANG, G. Habilidades da consulta na escuta médica. In: LEITE, A.J.M.; CAPRARA, A.; COELHO FILHO, J.M. (Orgs.). Habilidades de comunicação com pacientes e famílias. São Paulo: Sarvier, 2007. p.47-66. 